\title{
Pessoa e a doença do ocidente*
}

L eyla Perrone-M oisés**

* Comunicação apresentada no colóquio "Pessoa, unité, diversité, obliquité", no Centre Culturel de Cerisy-la-Salle em julho de 1997. Texto publicado em francês no volume Colloque de Cerisy - Pessoa, organizado por Pascal Dethurens e Maria Alzira Seixo, Paris, Christian B ourgois, 2000.

** Professora E mérita da USP. 
A temática da doença atravessa a obra inteira de Pessoa, assim como a de vários poetas e filósofos do fim do século XIX e começo do XX. Em Pessoa, essa temática própria dos decadentes e dos niilistas está ligada a certas características temperamentais e intelectuais, e adquire formas particulares.

Toda a sua obra pode ser encarada como uma busca de saúde, individual e coletiva. A obsessão com a doença aparece nos escritos pessoais do poeta (notas íntimas, cartas a amigos e a médicos) , em seus diagnósticos alargados à escala do homem em geral (escritos filosóficos) e da sociedade (escritos sociológicos e políticos). A doença ela mesma é freqüentemente tematizada em sua obra poética. E scusado dizer (suponho) que é a obra poética que nos interessa em última instância. Os escritos íntimos interessam aos biógrafos. Q uanto à obra filosófica, esta é fragmentária, desigual e contraditória. Desde as simples anotações de autodidata, datadas de sua juventude, até as brilhantes e paradoxais elucubrações da idade madura, os escritos filosóficos de Pessoa não têm maior interesse se os isolarmos de sua obra poética. Convém lembrar que, desde a idade de 22 anos, ele se autodefinia como “um poeta animado pela filosofia e não um filósofo provido de faculdades poéticas" ${ }^{1}$. Abandonemos portanto, de imediato, toda pretensão de definir a "filosofia" de Pessoa. Para evitar amálgamas citacionais, indicarei sempre a proveniência da citação (assinatura, gênero, data se possível), sem o que correse o risco de inventar, a partir de citações esparsas, um Pessoa pensador, único e coerente, que não existe em seus escritos e que, além disso, é menos interessante do que a entidade múltipla e filosoficamente perturbadora que ele criou e deixou

“I was a poet animated by philosophy, not a philosopher with poetic faculties". Pági nasínti mas e deauto-interpretação, ed. G. R. Lind \& J. Prado Coelho. Lisboa: Ática, s/d [1966], p. 13. (Essa obra será doravante designada pela sigla PIAI). 
dispersa. Num dos vários rascunhos de apresentação de suas obras completas (jamais editadas como tal), ele advertia: "A confecção destas obras não manifesta um qualquer estado de opinião metafísica" (PIAI, 100).

Em sua existência, Pessoa atravessou várias crises de depressão. A mais grave foi talvez a que ocorreu entre o segundo semestre de 1914 e o primeiro de 1915, e que ele descrevia em suas cartas a Armando Cortes-Rodrigues. Ele aí fala de "uma abulia absoluta ou quase absoluta", "ao nível do Livro do Desassossego", no qual ele trabaIhava então intensamente e que ele definia como "uma produção doentia". Essa depressão tinha várias agravantes: "lá fora, é a guerra", dizia ele. Nele mesmo, outra guerra grassava: ele desejava unificar, por autodisciplina, os elementos divergentes de seu caráter, incompatíveis com a alta missão humanitária e patriótica à qual se sentia destinado. Tudo indica, portanto, que a explosão em quatro pessoas, ocorrida segundo ele em março de 1914, só foi "triunfal” enquanto ficção poética; para o homem Pessoa, essa "explosão para dentro" nada resolveu. Pelo contrário, a descrição de sua "doença", em cartas imediatamente posteriores à dispersão heteronímica, é sempre acompanhada do desejo de unificar sua personalidade, condição para alcançar a desejada "saúde": “E stou hoje no fundo de uma depressão sem fundo [...] Sinto nas mãos o brinquedo partido que me deram por uma ironia de lata"2 .

Quatro anos após a "noite triunfal", em 1919, ele escreveu uma carta (não se sabe se enviada) a dois psiquiatras franceses, Hector e Henri Durville. Ele aí se descrevia como um "histérico-neurastênico" com predominância da neurastenia, e pedia informações acerca da terapia magnética, já que sua vida psíquica, dizia ele, "é uma espécie de curso de desmagnetismo pessoal" (PIAI, 69 a 74). Crises psíquicas semeIhantes se repetiram durante toda a sua vida e encontraram sua expressão na obra poética, sobretudo no Livro do Desassossego. Um mês antes de morrer, ele dizia numa carta: "O facto é que, desde o ano passado, tenho estado sob o influxo de estad os nervosos de diversas formas e feitios [ ...] Tenho-me sentido uma espécie de filme psíquico de um manual de psiquiatria, secção psiconevroses"3.

Essa depressão pessoal, mais ou menos crônica, inscreve-se num contexto mais largo, sociológico e cultural, que ele examina em seus escritos íntimos, filosóficos e políticos. Tais reflexões se assemelham a numerosas análises e prognósticos acerca da civilização ocidental, que proliferaram no fim do século $X I X$ e início do $X X$. $A$ ideologia do progresso, fundada sobre as conquistas científicas e técnicas desse período, tinha como contraponto o sentimento da decadência, expresso por numerosos filósofos, historiadores e escritores. Os estudos da patologia animal inspiravam o estudo de uma pretensa patologia social, suscetível ou não de tratamento. A temática da doença, individual ou coletiva, é pois característica daquela virada de século. Ela

Carta a Mário de Sá-Carneiro, 14 de março de 1916.

Carta a Tomás Ribeiro-Colaço, 10 de outubro de 1935. 
está presente em autores como Schopenhauer, Nietzsche, F reud (Mal-estar na civili zação) e Spengler (A deca dência do Ocidente), entre outros. Não se pode esquecer, também, que por circunstâncias históricas próprias, toda a reflexão portuguesa do fim do século XIX estava centrada no tema da decadência nacional.

Em sua juventude, Pessoa impressionou-se muito com a obra Dégénérescence, de $\mathrm{M}$ ax Nordau. Esse livro, que teve um êxito considerável, denunciava os poetas, os artistas, os revolucionários e os anarquistas como degenerados, perigosos para a civilização. Nordau via o decadentismo como uma doença social, "uma grave epidemia intelectual, uma espécie de peste negra", cujos sintomas ele descrevia, para estabelecer, em seguida, um "diagnóstico" e um "prognóstico". Pessoa deve ter-se reconhecido na descrição, feita por N ordau, dos principais traços do "degenerado": incapacidade de agir, gosto pelo devaneio, pelo vago, pelo paradoxo, pela metafísica, pelo misticismo, etc. Ele pertencia à geração descrita por Nordau:

Só a profunda fadiga experimentada pela geração sobre a qual a abundância das descobertas e das inovações caiu bruscamente, impondo exigências orgânicas que ultrapassavam suas forças, criou as condições favoráveis nas quais essas enfermidades puderam ganhar terreno de forma assustadora, e tornarem-se um perigo para a civilização ${ }^{4}$.

E mbora ele se tenha livrado logo da influência de Nordau, e tenha assinalado os "erros grosseiros" e as "asneiras" de sua obra5, Pessoa, que se desfez de tantos livros à medida que mudava de domicílio, conservou entretanto três livros deste autor em sua última biblioteca. Podemos ver as marcas dos diagnósticos de Nordau em certos fragmentos do Livro do Desassossego:

Pertenço a uma geração que herdou a descrença na fé cristã e que criou em si uma descrença de todas as outras fés. [...] Sem fé, não temos esperança, e sem esperança não temos propriamente vida.

Alguns, diz B ernardo Soares, estagnaram; outros se entregaram "ao culto da confusão e do ruído". E ele prossegue:

Mas outros, Raça do Fim, limite espiritual da Hora Morta, nem tiveram a coragem da negação e do asilo em si próprio. O que viveram foi em negação, em descontentamento e em desconsolo 6 .

NOR DAU, Max, Dégénérescence. Paris: Félix Alcan, 1899, v. II, p. 524.

Pági nas de estética, teoria e crítica literárias, ed. G. R. Lind \& J. Prado Coelho. Lisboa: Ática, s/d [ 1966], p. 158.

Livro do Desassossego, ed. J. Prado Coelho. Lisboa: Ática, 1982, v. I, p. 222-4. (E ssa obra será doravante designada pela sigla LD). 
Essa "R aça do Fim" parece fazer eco ao "homem do Crepúsculo dos Povos", denunciado por Nordau?.

Entretanto, esse diagnóstico vai assumir uma configuração particular em Pessoa-Soares. E m outro fragmento do Livro, que se inicia de maneira semelhante à do acima citado, ele toma o partido do decadente, ressaltando sua lucidez e justificando seu retraimento:

Nasci em um tempo em que a maioria dos jovens haviam perdido a crença em Deus [...] Assim, não sabendo crer em Deus [...] fiquei, como os outros, na orla das gentes, naquela distância de tudo a que comummente se chama a Decadência. A Decadência é a perda total da inconsciência: porque a inconsciência é o fundamento da vida. O coração, se pudesse, pararia.

A quem, como eu, assim, vivendo não sabe ter vida, que resta senão, como a meus poucos pares, a renúncia por modo e a contemplação por destino? (LD, I, 217-18).

A continuação do texto confirma, não apenas a opção pela contemplação, mas também a decisão de escrever sua obra, embora esta seja imperfeita, passageira e de valor incerto.

A leitura de $\mathrm{N}$ ietzsche também deixou marcas em seu espírito, marcas que o poeta, em geral, oculta ou minimiza. Num texto sobre o filósofo, Pessoa gracejava: “Os discípulos de Nietzsche são muito numerosos, no mundo inteiro, eentre eles há alguns que leram a obra do mestre" ${ }^{\prime 8}$. E le a havia lido. Suas afinidad es com $\mathrm{N}$ ietzsche são evidentes, apesar de todo o mal que diz do filósofo. Malgrado a recusa do germanismo de N ietzsche, a repugnância declarada por aquele "B árbaro do Norte", partidário da força e da potência, Pessoa é, como ele, um autor "para além do bem e do mal", um indisciplinador, e sua obra pertence àquela "escola da suspeita" referida pelo filósofo no prefácio a Humano, demasiadamente humano.

Sobre a questão precisa da doença ocidental, as colocações de Pessoa coincidem freqüentemente com as do filósofo. Nietzsche também se debateu, a vida toda, com a obsessão da doença, o medo da loucura e a busca compensatória da saúde. No prefácio acima citado, ele escrevia: “Aquilo de que eu necessitava sempre, com a maior urgência, para minha cura e meu auto-restabelecimento, era crer que eu não era o único dessa espécie, o único a ver as coisas dessa maneira". E , na seqüência do livro: "Seria o que eu vivi - a história de uma doença e de uma convalescença - unicamente minha experiência pessoal?" Zaratustra será o convalescente que canta, e toda a busca do filósofo irá na direção da "grande saúde". Sua reflexão geral sobre o niilismo e a vontade de potência pode ser vista como o alargamento, em termos filosóficos, dessa temática pessoal e geracional.

Op. cit., v. I, p. 38.

Textos filosófi cos. Lisboa: Ática, 1968, v. I, p. 135. 
Como Nietzsche e outros pensadores do mal-estar na civilização, B ernardo Soares estabelece um diagnóstico:

Desde o meio do século dezoito que uma doença terrível baixou progressivamente sobre a civilização. Dezassete séculos de aspiração cristã constantemente iludida, cinco séculos de aspiração pagã perenemente postergada - o catolicismo que falira como cristismo, a renascença que falira como paganismo, a reforma que falira como fenómeno universal. $O$ desastre de tudo quanto se sonhara, a vergonha de tudo quanto se conseguira [...]

Isto caiu nas almas e envenenou-as (LD, II, 204).

Desse diagnóstico decorre a proposta de um movimento neopagão. Na apresentação do "neopaganismo", António Mora explica seus fundamentos:

[Tudo] contribui para que se mantenha, íntegra e indesfeita, a decadência, já normal, da época. Conseguimos esse desiderato de alienado - a normalização da anormalidade. [...]

Nós realizamos, modernamente, o sentido preciso daquela frase de Voltaire, onde diz que, se os mundos são habitados, a terra é o manicómio do Universo. Somos, com efeito, um manicómio, quer sejam ou não habitados os outros planetas. Vivemos uma vida que já perdeu de todo a noção de normalidade, e onde a higidez vive por uma concessão da doença.

Vivemos em doença crónica, em anemia febricitante. O nosso destino é o de não morrer por nos termos adaptado ao stado de (perpétuos) moribundos (PIAI, 299-300).

A busca das razões dessa doença coletiva leva todos os pensadores da virada do século à reflexão sobre nossas raízes culturais gregas e judias. De fato, a cultura ocidental é o resultado, sempre problemático, de uma tentativa de conciliação de princípios inconciliáveis: a aceitação incondicional dos mandamentos recebidos e a busca do conhecimento pelo entendimento; a L ei e o Logos; o monoteísmo e o politeísmo; a culpabilidade e a inocência. Esses pensadores crepusculares fazem, cada um à sua maneira, o processo da lei monoteísta, que nos sobrecarregou de culpa, do cristianismo que nos trouxe o desprezo pela vida terrena, o gosto pelo sacrifício e o sentimentalismo. E todos sonham com uma Antigüidade grega que, por comparação, parecia mais favorável à realização plena do homem, à conciliação do pensamento com o mundo sensível.

Pessoa tentou resolver essas contradições, multiplicando-se em personalidades "judias" e "gregas". Sendo de ascendência judaica (cristão novo), concebeu heterônimos neopagãos. E nquanto estes tentavam reencontrar "a claridade do meio- 
dia" da Antigüidade greco-romana, o "ele mesmo" e alguns outros cultivavam um ocultismo de origem judaica, cabalístico ou teosófico. Assim, Fernando Pessoa "ele mesmo", Alexander Search e R afael B aldaya são “judeus", enquanto Alberto Caeiro, Álvaro de Campos, Ricardo Reis, António Mora e Frederico R eis são "gregos", ou desejariam sê-lo. De um modo ou de outro, todos enfrentam a dificuldade de conciliar os princípios cognitivos gregos com a moral judaico-cristã?.

A heteronímia pessoana foi, entre outras coisas, a encenação de uma alternativa: "saúde" grega ou "doença" cristã. Como Nietzsche em O Anti-Cristo, Pessoa atribui a infelicidade do homem ocidental au cristianismo, ou mais precisamente, ao "cristismo" (não é o próprio Cristo que é incriminado, mas seus seguidores). Num texto de apresentação do "sensacionismo", escrito provavelmente em 1916, ele explica:

\begin{abstract}
A sensação da realidade era directa nos gregos e nos romanos, em toda a 'antigüidade' clássica. Entre a sensação e o objecto - fosse esse objecto uma cousa do exterior ou um sentimento - não se interpunha uma reflexão, um elemento qualquer estranho ao próprio acto de sentir. [...]

Passada pelas almas a longa doença chamada cristianismo, esmiuçado doentiamente o espírito por si próprio, a clareza da sensação perturbou-se. A presença no pensamento das idéias de espírito, de Deus, de outra vida, concebidas como o eram, levaram a uma decomposição da R ealidade, qual os gregos a haviam concebido. Entre a sensação e o objecto dela - fosse esse objecto uma cousa exterior ou um sentimento - intercalara-se todo um mundo de noções espirituais que desvirtuava a visão directa e lúcida das cousas (PIAI, 170).
\end{abstract}

No mesmo ano, o heterônimo António Mora escreve: “O paganismo aparece com a saúde, desaparece com o ad oecimento do género humano" (PIAI , 286).

O desdobramento em heterônimos, e a teorização posterior desse fenômeno, foram um recurso heroico visando à saúde mental do homem Pessoa e, como um suplemento generoso, à saúde de seus semelhantes menos providos de gênio, nós todos. Não podendo suportar todas as contradições que seu raciocínio e sua autoanálise obsessiva Ihe mostravam, ele "transbordou". Assim como, do ponto de vista psicanalítico, cada heterônimo correspondia a um encaminhamento pulsional particular, cada um de seus alteregos assumiu uma via filosófica própria. O poeta tentou colocar cada heterônimo (ortônimo incluido) numa posição senão isenta da doença ocidental, pelo menos suportável sem excessivas contradições. Criou assim um politeísmo pessoal, oposto ao culto monoteísta do Eu.

O neopaganismo pessoano não é um simples programa estético, apenas um dos numerosos neoclassicismos que floresceram em seu tempo, mas um progra- 
ma de salvação pessoal e civilizacional. Quando R icardo R eis expõe os objetivos do movimento, ele rejeita as formas contemporâneas de volta aos gregos:

Reconstruir o paganismo envolve, pois, como primeira acção intelectual, fazer renascer o objectivismo puro dos gregos e dos romanos. Tudo o mais que se tente não passa de reprodução estéril dos elementos secundários e mesmo acessórios do paganismo antigo. Por isso nunca houve, adentro da civilização cristã, tentativa alguma que de pagã mereça o nome, embora várias tenha havido com sobrada pretensões a esse respeito. Não exemplifiquemos exaustivamente, que a tarefa, sobre ser inútil, seria penosamente longa. Enumerar todo o lixo cristão com pretensões pagãs dos Matthew Arnolds, dos Oscar Wildes e dos Walter Paters do baixo-cristismo, seria enfadonho e desolador (PIAI, 234).

Nietzsche não recebe melhor tratamento:

O ódio de Nietzsche ao cristismo aguçou-lhe a intuição nestes pontos. Mas errou, porque não era em nome do paganismo greco-romano que ele erguia o seu grito, embora o cresse; era em nome do paganismo nórdico de seus maiores. $\mathrm{E}$ aquele Diónisos, que contrapõe a Apolo, nada tem com a Grécia. É um Baco alemão. Nem aquelas teorias desumanas, excessivas tal qual como as cristãs, embora em outro sentido, nada devem ao paganismo claro e humano dos homens que criaram tudo o que verdadeiramente subsiste, resiste e ainda cria adentro do nosso sistema de civilização (PIAI, 236).

Demasiadamente lúcido para acreditar que se poderiam apagar séculos de história do pensamento e da sensibilidade, para recomeçar da estaca zero, Pessoa e seus heterônimos examinam pacientemente as acomodações possíveis. $R$ icardo R eis distingue os pagãos ortodoxos (ele mesmo, Caeiro e Mora) daquele "outro ramo" (o de Fernando Pessoa "ele mesmo") que "aceita a sensibilidade moderna e os seus resultados mórbidos, mas tendo-os, ao mesmo tempo, por inirradicáveis", acreditando que "o neopaganismo deve seguir a esteira do cristismo" ( PIAI, 225 e 226). No entanto, António Mora, mais realista do que o rei, não reconhece a ortodoxia de Reis. Ele observa que a indiferença de Reis é um sinal de decadência (PIAI, 301). Quanto a Álvaro de Campos, a descrição do "cristismo" feita por R icardo R eis parece assentar-Ihe como uma luva: "fenómeno doentio, ele apresenta a oscilação característica da histeria, onde comumente se vive nos extremos e nos auges das emoções, e onde tudo é possível menos o equilíbrio e a sobriedade" (PIAI, 236). Assim, todos se pretendem pagãos, e todos acabam por ser irremediavelmente cristãos e decadentes. Todos aspiram à saúde, mas detectam continuamente suas respectivas doenças.

O belo programa da coterie pessoana parece ter falhado, no que concerne ao objetivo de recuperar a saúde perdida. A própria heteronímia, concebida original- 
mente como uma brincad eira ou uma esperteza que alcançaria, ao mesmo tempo, o objetivo estético de suprir uma "falta de literatura" em seu país, e o objetivo psicológico pessoal de compensar uma falta de unidade e de coerência, desemboca numa angustiante falta de ser. A heteronímia não curou Pessoa. Pelo contrário, como tudo o mais, ela é suspeita de morbidez: “É, não sei se um privilégio ou uma doença, a constituição mental que a produz", escreve ele, por volta de 1930, num dos prefácios possíveis às suas obras completas (PIAI, 95). A obra pessoana parece ser, como a terra para Voltaire, um manicômio. O ortônimo, os grandes heterônimos e o semiheterônimo B ernardo Soares apresentam todos sintomas neuróticos ou psicóticos. Fernando Pessoa "ele mesmo" sofre de melancolia e da sensação de ausência de si mesmo; Ricardo R eis sofre de depressão e abulia; Álvaro de Campos é histérico e ciclotímico em sua juventude, depressivo em sua maturidade; B ernardo Soares sofre de tudo isso ao mesmo tempo. Os quatro são decadentes, pois mesmo na vertente futurista de Álvaro de Campos, o ortônimo detecta a atração que os decadentes têm pela força, pelo dinamismo e pela saúde (PIAI, 177).

A doença de que todos sofrem é psíquica. O mal-estar em que vivem é o malpensar em que sentem, diz o ortônimo, reconhecendo que "há doenças piores do que as doenças", "angústias mais reais do que as que a vida nos traz". O s estados doentios de Álvaro de Campos também são raramente físicos. E m seu poema de juventude, ele precisa: “É antes do ópio que a minh'alma é doente. Sentir a vida convalesce e estiola" ("O piário"). E , mais tarde, quando sofre de um mal físico, este se revela causado por uma falta metafísica: “Q ue grande constipação física! Preciso de verdade e de aspirina!" De qualquer maneira, Campos está sempre num estado psicologicamente doentio, oscilando entre a febre e o abatimento, aspirando ao repouso nos braços da Noite, "enfermeira antiqüíssima". Q uanto a B ernardo Soares, este reivindica a doença absoluta: "D oem-me a cabeça e o universo" (LD, II , 170).

A filiação de todos esses doentes ao mestre Caeiro é uma busca de saúde. Caeiro seria a salvação: “A legrai-vos, todos vós que chorais na maior das doenças da H istória! O grande Pã renasceu!" (PIAI, 332). O mestre parece possuir o segredo da saúde: “Ah, como os mais simples dos homens / São doentes e confusos e estúpidos / Ao pé da clara simplicidade / E saúde em existir / Das árvores e das plantas!" O mundo real, a natureza, são para ele a saúde; já o conceito de N atureza, com maiúscula, é para ele "uma doença de nossas idéias". O segredo residiria na supressão do pensamento, que faz adoecer o pensador: "O que penso eu do mundo? Sei lá o que penso do mundo! Se eu adoecesse pensaria nisso". Pré-socrático, nominalista, prémetafísico, Caeiro estaria isento da doença ocidental posterior.

Mas a grande saúde de Caeiro é factícia. Caeiro é um plano de saúde intelectual, e não um sujeito sadio. Quando adoece, ele resiste bravamente: "E stou doente. M eus pensamentos começam a estar confusos / $M$ as o meu corpo, tirado às cousas, 
entra nelas [...] E uma grande libertação começa a fazer-se em mim". E m sua obravida, há períodos doentios: o intermédio do "pastor amoroso" e quatro poemas escritos "em plena doença". Caeiro denega que a doença seja uma negação da saúde: “Por isso essas canções que me renegam / Não são capazes de me renegar / E são a paisagem da minha alma de noite, / A mesma ao contrário..." Fica então evidente que a saúde e a doença não são simplesmente vividas pelo ser natural que ele pretende ser; elas são pensadas em termos de lógica binária, uma não podendo existir sem a outra. A terceira dessas canções doentias é construída em anáfora, com quatro proposições iniciadas por "Quem me dera eu fosse", exprimindo todas o desejo de ser natural e insensível como as coisas e os animais, isto é, o desejo de seguir à risca o "programa" Caeiro. E o último verso, tão pouco Caeiro, poderia ter sido escrito pelo melancólico ortônimo: "Antes isso do que ser o que atravessa a vida / Olhando para trás de si e tendo pena..."

No conjunto dos poemas de Caeiro, as alusões à sua boa saúde física e mental são tão numerosas e explícitas que parecem suspeitas. Como bem disse E duardo L ourenço, Caeiro é uma "ficção consoladora", "a cura fulgurante para o que não tem cura"10. E m outro ensaio, o mesmo crítico observa que Caeiro representa uma tentativa de escapar às "duas doenças" (a do pensamento e a da alma) e de eludir a desconfiança ontológica com relação às palavras:

Na medida em que Pessoa crê, ou finge crer, que o milagre aconteceu, que o sentido veio aderir à palavra que pretende ser o seu duplo, a poesia-Caeiro, Caeiro-poema, Caeiro-ser é um acontecimento mais do que humano. Poderíamos pensá-lo sob a figura do anjo, se essa figura não destoasse tanto da encarnação do paganismo que Caeiro é, aos olhos de Pessoa. Um anjo, mas também um monstro, se compreendemos, como Pessoa compreendeu, que Caeiro é contra a natureza ${ }^{11}$.

Se considerarmos a saúde e a doença como estados naturais, Caeiro não pode ser, a rigor, nem sadio, nem doente, e ele tem razão quando diz que sua "doença", suposta anormal em termos de lógica, é tão compatível com seu ser teórico quanto a saúde dita normal.

Se aceitamos, com Eduardo Lourenço, que Caeiro não passa de uma ficção, somos levados a ver a realidade onipresente da doença na obra pessoana. É a doença que nela predomina, porque ela é a manifestação psico-fisiológica de um desacordo profundo entre o pensamento "pagão" e o sentimento "cristão". A do-

LOURE NÇO, Eduardo. Pessoa revisitado. Porto: Editorial Nova, 1973. p. 37, 55 e 161.

I dem, "Poésie et philosophie chez Pessoa", texto datilografado, tradução minha. (Publicado posteriormente in Pascal Dethurens \& Maria Alzira Seixo (ed.), Colloque de Cerisy - Pessoa, p. 128. 
ença não é apenas sua, é ocidental. Depois de todas as tentativas de mostrar o caminho pelo qual o homem ocidental poderia recuperar a saúde perdida, Ricardo R eis é forçado a reconhecer: "Está envenenada para sempre a alma humana". O paganismo está morto, o cristianismo e "os poderes da sombra" triunfaram. Só resta, ao pagão moderno, o exílio "no meio de uma civilização inimiga", o recurso ao estoicismo ou ao epicurismo (PIAI, 322-23).

Assim, a obra inteira de Pessoa é a exposição de estados doentios. A maioria de seus poemas e todo o Li vro do Desassossego têm por tema o mal-estar do sujeito que, à força de lucidez e de autoanálise, anula todo e qualquer objeto, inclusive ele mesmo. O estado "normal" dos poetas da coterie (com exceção da ficção-Caeiro) é a depressão, com o que dela decorre: o pessimismo, a melancolia, a sensação de malogro, a renúncia a qualquer verdade e a qualquer ação. Uma pergunta parece então impor-se: por que essa obra "decadente" foi sendo, cada vez mais, reconhecida como uma obra capital da modernidade? Por que, nesta outra virada de século, o Livro do Desassossego se transformou em best seller internacional, e seu autor em personalidade fecundante para tantos artistas, saindo do domínio da poesia, que era o seu, para inspirar, em toda parte, romancistas, pintores, músicos, cineastas e teatrólogos?

Podemos pensar que a doença ocidental, cujos sintomas essa obra expõe, não está curada, e que ela até se agravou, espalhando-se pelo mundo todo. Chegados a esta nova virada de século, sem que os problemas levantados pelos pensadores do mal-estar de nossa civilização fossem resolvidos, estaríamos todos adaptados ao "estado de perpétuos moribundos" a que se referia António Mora. Os leitores de Pessoa seriam, pois, doentes que gostam de ver exposta sua doença. Essa resposta, embora não totalmente falsa, é insuficiente, na medida em que ela supõe uma hipocondria ou um masoquismo generalizado nos leitores de poesia. A resposta não deve, pois, ser procurada no lado do referente, mas no lado da forma.

Primeiramente, na obra sombria de Pessoa, o leitor encontra muitas compensações. A pesar do tom geral de pessimismo, essa obra se caracteriza por uma inteligência, uma ironia e um humor que procedem de uma extraordinária vitalidade. E mbora deixada em estado inacabado (e este é um de seus encantos), essa obra materialmente enorme, prosseguida ao longo de uma vida com uma espantosa persistência, é um investimento formidável de energia. Pessoa escreveu miIhares de páginas para dizer que ele não era nada, que só fingia, que afinal nada valia a pena, inclusive e sobretudo o esforço de escrever. E sse paradoxo, e o paradoxo final de ter encontrado postumamente milhares de leitores, parece a última mágica executada pelo extraordinário prestidigitador que ele foi.

O retumbante êxito desse râté não é nem filosófico, nem psicológico; seu êxito é poético. Que me perdoem por enunciar essa evidência, mas acho necessário fazê-lo, 
já que os cultores de Pessoa parecem por vezes esquecê-la. No entusiasmo provocado pelo reconhecimento internacional do poeta, tentaram transformá-lo em personagem positivo, exemplar e tutelar: mestre de pensamento, guia de conduta, patriota e propagandista de Portugal, profeta da Europa, guru esotérico ou santo. Ora, a obra de Pessoa não traz nenhuma boa nova, exceto a de sua originalidade estética.

As formas surpreend entes e miraculosamente justas encontradas pelo poeta para expor sua (nossa) doença, eis o que explica esse êxito. Álvaro de Campos dizia, a respeito de Fernando Pessoa "ele mesmo", algo que se aplica a todos os heterônimos: "sua força reside na análise intelectual do sentimento e da emoção, por ele levada a uma perfeição que quase nos deixa com a respiração suspensa" (PIAI , 149). De fato, a força reside na perfeição da análise mais do que naquilo que é analisado, e que, na verdade, é inteiramente produzido por essa perfeição.

O próprio Pessoa refletiu, muitas vezes, sobre os objetivos visados por sua obra. Por volta de 1916, ele escreveu: “A finalidade da arte é simplesmente aumentar a autoconsciência humana. O seu critério é a aceitação geral (ou semigeral), mais tarde ou mais cedo, pois é essa a prova de que, na realidade, ela tende a aumentar a autoconsciência entre os homens" (PIAI, 186). A autoconsciência não éa cura; era, aliás, por excesso de autoconsciência que Pessoa se sentia doente. Como nos ensina a psicanálise, a possibilidade da cura reside na capacidade de dizer o próprio mal. Bernardo Soares, cuja aspiração suprema era a de "dizer", indica o caminho pelo qual Pessoa salvou-se e pode, efetivamente, ajudar seus leitores: "A maioria da gente enferma de não saber dizer o que vê e o que pensa" (LD, II , 261). Se encontrar as palavras para dizer o sofrimento é um caminho de saúde, encontrar as palavras exatas da poesia, e colocá-las à disposição dos outros, é o papel benfazejo dos poetas. "Creio que dizer uma coisa é conservar-Ihe a virtude e tirar-lhe o terror" (LD, II , 264); “dizer é renovar" (LD, II , 261). Para B ernardo Soares, dizer não é desvendar a realidade, mas instaurá-la:

Toda a literatura consiste num esforço para tornar a vida real. Como todos sabem, ainda quando agem sem saber, a vida é absolutamente irreal na sua realidade directa; os campos, as cidades, as idéias, são coisas absolutamente fictícias, filhas da nossa complexa sensação de nós mesmos. São intransmissíveis todas as impressões salvo se as tornarmos literárias. (LD, II, 262).

Do que nos cura a arte, senão da vida? perguntava Pasolini no Evangel ho segundo São Mateus. A cura pela arte consiste, como sabem os artistas e sabia Pessoa, na capacidade de dar uma forma a nossa enfermidade. 